\title{
An in-vivo model to examine the electromyographic activity of isolated myometrial tissue from pregnant sheep
}

\author{
S. J. Lye and C. L. Freitag \\ Departments of Obstetrics/Gynaecology and Physiology, Research Institute, St Joseph's Hospital, \\ University of Western Ontario, London, Ontario, Canada N6A 4V2
}

\begin{abstract}
Summary. Strips $(2.5 \times 3.5 \mathrm{~cm})$ of myometrium alone (MYO) or endometrium/ myometrium (ENDO/MYO) were removed from the pregnant horn of sheep (Day 110 of gestation) and transplanted to sites within the omental fat. These explants developed regular bursts of electromyographic (EMG) activity over a period of 7-10 days, as well as a dose-dependent stimulatory response to oxytocin $(50-200 \mathrm{mU}$ i.v. $)$. The frequency (per $2 \mathrm{~h}$ ) of EMG bursts in the MYO (5.3 \pm 0.2$)$ and ENDO/MYO (5.2 \pm 0.3$)$ explants was significantly greater $(P<0.05)$ than that of the uterine myometrium $(3 \cdot 0 \pm 0 \cdot 1)$, while burst duration (min) in MYO $(4 \cdot 1 \pm 0 \cdot 2)$ and ENDO/MYO $(4 \cdot 1 \pm 0 \cdot 2)$ explants was significantly $(P<0.05)$ less than in the uterine myometrium $(7 \cdot 3 \pm 0 \cdot 1)$. The EMG bursts were asynchronous between the explants and uterus, although systemic administration of oxytocin produced a synchronous burst of EMG activity in all three tissues. No differences in EMG activity or responsiveness were apparent between MYO and ENDO/MYO explants. Histological examination of the explant tissue revealed the presence of smooth muscle fibres regularly orientated into two layers; some loss of endometrial tissue was apparent in ENDO/MYO explants. To validate the mechanical integrity of this model we examined the in-vitro contractile activity of myometrial strips prepared from the explants. The strips developed regular spontaneous contractions and demonstrated a dose-dependent stimulation in response to the addition of oxytocin $\left(10^{-10}\right.$ to $\left.10^{-4} \mathrm{M}\right)$ to the bath fluid. These results suggest that spontaneous contractures during pregnancy are probably not due to pulsatile release of stimulants into the systemic circulation, or the direct diffusion of stimulants from intrauterine tissues to the myometrium but are probably caused by factors within the myometrium itself.
\end{abstract}

Keywords: pregnant sheep; isolated myometrium; electromyography; in-vivo model

\section{Introduction}

The occurrence, throughout pregnancy in the ewe, of low-frequency, low amplitude uterine contractions has been reported by a number of investigators (Hindson \& Ward, 1973; Nathanielsz et al., 1976; Van der Weyden et al., 1981; Harding et al., 1982; Lye et al., 1983; Sigger et al., 1984a; Garcia-Villar et al., 1984). They have been termed 'contractures' by Nathanielsz et al. (1976) to differentiate them from the short-duration, high-frequency 'contractions' of labour. Contractures are first detectable between Days 28 and 60 (Van der Weyden et al., 1981; Sigger et al., 1984a), continue to term ( $\sim$ Day 145 ), and typically occur with a frequency of $0.5-3 \mathrm{~h}$, a duration of 5-8 min, and an amplitude of $2-8 \mathrm{mmHg}$ (Van der Weyden et al., 1981; Harding et al., 1982; Lye et al., 1983). Over $95 \%$ of these contractures are associated with a burst of myometrial electromyographic activity of a similar duration (Harding et al., 1982). Similar contractures during pregnancy have been observed in a number of species including man (Csapo \& Sauvage, 1968), monkey (Germain et al., 1982), guinea-pig (Porter, 1971),

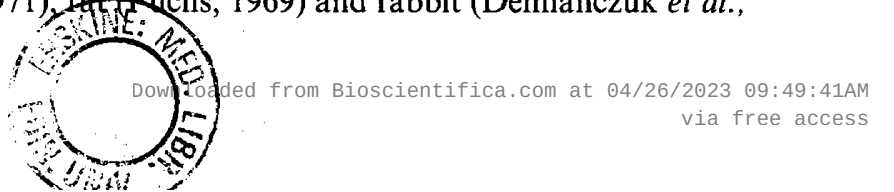


1984). Contractures have also been observed in pregnant sheep carrying dead fetuses (Harding et al., 1982) and in non-pregnant sheep (Ruckebusch \& Bueno, 1976; Harding et al., 1982; Windmoller et al., 1983), indicating that the fetus plays little or no role in their production.

Despite the wealth of information describing their occurrence, very little is known about the genesis of contractures or their role during pregnancy. In the sheep, contractures have been reported to be associated with transient decreases in uterine blood flow (Sunderji et al., 1984) and fetal $\mathrm{PaO}_{2}$ (Jansen et al., 1979; Lye et al., 1984), short-term increases in fetal plasma ACTH (Lye et al., 1985), and changes in fetal sleep state and breathing movements (Nathanielsz et al., 1980).

Several explanations have been proposed to account for the regular occurrence of contractures. These include (1) an inherent myogenic activity of the entire reproductive tract (Toutain et al., 1983; (2) diffuse stimulation of a nerve net (Harding et al., 1982); and (3) hormonal stimulation by prostaglandins (El Badry et al., 1984) or systemic oxytocin (Garcia-Villar et al., 1983).

In sheep, oxytocin is released into the systemic circulation in a pulsatile fashion both during the oestrous cycle and during pregnancy (Mitchell et al., 1982). In addition, we have shown that physiological bolus injections of oxytocin into the peripheral circulation produced increases in intrauterine pressure and electromyographic activity, both qualitatively and quantitatively similar to spontaneous contractures (Lye et al., 1984). However, Garcia-Villar et al. (1983) have failed to detect increases in peripheral plasma oxytocin concentrations associated with spontaneous contractures.

In this study we have developed an in-vivo myometrial explant preparation to examine the contribution of local vs systemic factors in the genesis of contractures during pregnancy. This preparation involves the transplantation of myometrial tissue from the pregnant uterus to another site within the abdominal cavity. It differs from the other models (Wagner, 1975; Sigger et al., 1984b) in (1) maintaining the in-situ degree of stretch on the tissue (a major factor contributing to the contractile activity of the myometrium: Wathes \& Porter, 1982); (2) allowing the investigation of myometrial tissue with and without attached endometrium, and (3) confirming the mechanical integrity of the explants by examining their spontaneous contractile activity and responsiveness to oxytocin in vitro upon conclusion of the study.

Specifically, this study questioned: (1) whether isolated myometrial tissue developed spontaneous contractures and responded to oxytocin in vivo, and (2) if so, whether the spontaneous contractures were synchronized with those of the uterus (suggestive of a systemic pulsatile stimulation), or whether they were asynchronous (suggestive of an independent, possibly myogenic influence).

\section{Materials and Methods}

\section{Surgical preparation}

Five crossbred sheep of known single insemination dates were used. Surgery was performed at Days $110-113$ of gestation under general anaesthesia $\left(\mathrm{N}_{2} / \mathrm{O}_{2} /\right.$ halothane). The uterus was exposed through a ventral mid-line laparotomy, and the fetal position adjusted so that when the fetal head was pulled through the abdominal incision it was covered by the antimesometrial uterine tissue. An incision on 3 sides of a rectangle $(2.5 \times 3.5 \mathrm{~cm})$ was made in the antimesometrial surface of the myometrium over the fetal head. Great care was taken to avoid incision into the endometrium. The myometrium (circular and longitudinal layers intact and unseparated) was then peeled away from the underlying endometrium to form a flap of tissue; the flap was cut away from the uterus and attached at its four corners to a stainless-steel frame $(2.5 \times 3.5 \mathrm{~cm})$. The strip was orientated such that the longitudinal muscle layer of the myometrium was parallel to the long axis of the frame. A continuous running suture was then used to attach the cut edge of the myometrial strip firmly to the border of the stainless-steel frame. This resulted in the myometrium being stretched to its approximate in-situ dimensions. A pair of multi-filament stainless-steel electrodes (Cooner Wire, Chatsworth, CA, U.S.A.) was sutured into the myometrium (full thickness) at either end of the explant (1.5 cm apart) to record electromyographic (EMG) activity.

A second rectangular incision $(2.5 \times 3.5 \mathrm{~cm})$ was made in the uterus, this time passing through the myometrium and endometrium. The strip was removed without interfering with the junction between the two tissue layers, attached to a stainless-steel frame and instrumented with electrodes as described above. 
The myometrial (MYO) and endometrial/myometrial (ENDO/MYO) explants were then sutured into folds within the omental fat, such that they were not able to make contact with each other or the uterus. Reference electrodes were sutured into the omental fat.

The fetal head and neck were then delivered through the uterine incision and catheters (V4, Bolab, Lake Havasu City, AZ, U.S.A.) inserted into the fetal jugular vein and carotid artery. This allowed the collection of fetal blood to monitor fetal health by measurement of $\mathrm{PaO}_{2}, \mathrm{PaCO}_{2}, \mathrm{pH}$, etc. Analysis of these parameters revealed that in all pregnancies the fetus remained healthy throughout the study period. A catheter was also placed into the amniotic cavity so that intrauterine pressure (IUP) could be measured. The incisions in the fetal membranes and uterus were closed and a pair of electrodes sutured into the antimesometrial surface of the myometrium. Catheters (VI 1, Bolab) were inserted $20 \mathrm{~cm}$ into the maternal femoral artery and vein such that the catheter tips lay in the abdominal aorta and vena cava respectively, about $5 \mathrm{~cm}$ proximal to the bifurcation of these vessels.

The animals received post-surgical analgesia and also prophylactic antibiotics to the ewe and fetus (Lye et al., 1983). Catheters were flushed daily with sterile heparinized saline $(4 \mathrm{U} / \mathrm{ml})$, under aseptic conditions.

\section{In-vivo myometrial activity recording}

Myometrial activity (EMG activity from myometrial electrodes, and IUP from the amniotic fluid catheter) was monitored continuously from Day 1 after surgery in 3 animals and from Days 10-12 after surgery in the remaining 2 animals. The EMG signal from the uterus and the explants was processed through a Grass wide-band AC preamplifier, Model 7P511J using a half-amplitude low frequency filter of $0.3-1 \mathrm{~Hz}$ and a half-amplitude high frequency filter of $10 \mathrm{kHz}$. IUP was monitored by connecting the amniotic fluid catheter to a Statham P23 pressure transducer and processing the signal through a Grass low-level DC preamplifier (7P1). Both signals were recorded using a Grass 78 polygraph.

Oxytocin responsiveness. To assess the physiological integrity of the explants and the time course of uterine and explant response to stimulants within the systemic circulation, graded doses of oxytocin (Syntocinon: Sandoz, Dorval, Quebec: 50,100 and $200 \mathrm{mU}$ in $0.2,0.4$ and $0.8 \mathrm{ml}$ saline $(0.9 \% \mathrm{w} / \mathrm{v} \mathrm{NaCl})$ respectively) were administered to the ewes beginning on Day 125 of gestation. To ensure that the recorded myometrial EMG and IUP activity after oxytocin was not due to a spontaneously occurring contracture, the mean interval between spontaneous contractures (or EMG bursts) was first calculated (i.e. the contracture-contracture interval). For explants, this interval ranged from 15 to $40 \mathrm{~min}$ and for the uterus approximately 30 to $120 \mathrm{~min}$, although within any one animal it remained fairly constant (Lye et al., 1984). Administration of saline at this time causes no change in myometrial electrical activity (Lye et al., 1985). In preliminary studies (see 'Results') there was an indication that the time from the previous spontaneous contracture might affect the response of the uterus and myometrial explants to oxytocin. We therefore monitored EMG activity until bursts were observed in both explants and the uterus at approximately the same time. Oxytocin, at the appropriate dose, was then administered as a bolus via the maternal femoral vein catheter (usually between 5 and $10 \mathrm{~min}$ after the spontaneous EMG bursts). At this time a spontaneous contracture in these tissues would not be expected to occur. At least $60 \mathrm{~min}$ was allowed to elapse before administration of the next dose of oxytocin. Data from recent studies in which up to 5 injections of oxytocin $(100 \mathrm{mU})$ are given to pregnant sheep within a 12-h period indicate that there is no tachyphyllaxis to oxytocin administered under these conditions (S. J. Lye, unpublished).

\section{Analysis of chart records}

Spontaneous activity. Traces were divided into 2-h segments. The frequency and duration of EMG bursts and the frequency, duration and maximum amplitude of uterine contractures per 2-h period were recorded. An EMG burst was defined as a continuous firing of EMG electrodes of amplitude $>50 \mu \mathrm{V}$ (for the explants) or $>200 \mu \mathrm{V}$ (for the uterus) and of duration $>3 \mathrm{~min}$. Uterine contractures were defined as increases in IUP of at least $2 \mathrm{mmHg}$ lasting for $>3 \mathrm{~min}$ and associated with an EMG burst from the uterine electrodes. Uterine contractures were separated by at least 20 min electrical quiescence at Days $120-140$ of gestation.

Oxytocin response. The response of the myometrium to oxytocin was analysed over the 30-min period after oxytocin administration. The response of the MYO explant and the uterine myometrium was assessed by integrating the EMG signal using a Grass polygraph integrator (7P10). The response of the ENDO/MYO explant was measured using arbitrary units (frequency $\times$ duration $\times$ amplitude of EMG bursts).

\section{Contractile integrity of explants}

To establish that the contractile integrity of the myometrial tissue had been maintained when explanted to the omental fat, we examined (a) the ability of the myometrium to develop spontaneous contractions and respond to oxytocin in vitro, and (b) the explant histologically for the presence of organized smooth muscle fibres.

At the conclusion of the experiment the animals were killed with an overdose of pentobarbitone sodium at Days 132-136 of gestation. The explants were quickly dissected free of omental tissue. Half of each explant was frozen for other biochemical studies; the remainder was placed in Krebs-Ringer-Bicarbonate buffer (KRB) for contraction studies (see below). A small strip from this explant tissue was processed as described below for histological 
examination. A sample $(5 \times 5 \mathrm{~cm})$ of myometrial tissue from the pregnant uterine horn was also taken for in-vitro contractile studies and histological examination.

In-vitro contraction study. Small strips (about $10 \times 2 \mathrm{~mm}$ ) of myometrial tissue were cut from the explant and uterine samples. Each strip was placed in a jacketed organ bath (volume $=15 \mathrm{ml}$ ) at $37^{\circ} \mathrm{C}$ in $\mathrm{KRB}$ (containing $4.6 \mathrm{mM}-$ $\mathrm{KCl}, 1.16 \mathrm{mM}-\mathrm{MgSO}_{4} .7 \mathrm{H}_{2} \mathrm{O}, 1.16 \mathrm{~mm}-\mathrm{NaH}_{2} \mathrm{PO}_{4} \cdot \mathrm{H}_{2} \mathrm{O}, 2.5 \mathrm{~mm}-\mathrm{CaCl}_{2} .2 \mathrm{H}_{2} \mathrm{O}, 115.5 \mathrm{~mm}-\mathrm{NaCl}, 21.9 \mathrm{~mm}-\mathrm{Na} 2 \mathrm{HCO}_{3}$, $11.1 \mathrm{~mm}$-dextrose) at pH 7.4 and bubbled with $95 \% \mathrm{O}_{2}: 5 \% \mathrm{CO}_{2}$. Cotton thread was used to attach the myometrial strip to a fixed hook and a force displacement transducer (Grass model FT03) to measure isometric tension. The signal was processed through a low level DC preamplifier (7PI) and monitored on a Grass 78 polygraph. The myometrial strips were initially placed under I $g$ tension and allowed to equilibrate over a period of at least $1 \mathrm{~h}$. The dose-response of the myometrium to oxytocin was examined by adding 10-fold increasing doses of this hormone in the range $10^{-10}-10^{-4} \mathrm{M}$, at 15 -min intervals. The frequency of contractions and mean resting tension was measured for each $15 \mathrm{~min}$ period and the contractile activity expressed, arbitrarily, as the multiple of these two values.

Histology. The small strips of explant and uterine myometrium for histological examination were pinned out to their approximate in-vivo dimensions and placed in $10 \%$ neutral buffered formalin. Subsequently they were dehydrated in ethanol and cleared in xylene. The myometrial strips were embedded in Tissue Prep (Fisher Scientific, Fair Lawn, N.J., U.S.A.), sections of the strips were cut and stained using a routine haematoxylin and eosin stain.

\section{Statistical analysis}

The results are expressed as mean ( \pm s.e.m.). When appropriate, differences between groups were examined for statistical significance by Student's $t$ test or by analysis of variance, having first confirmed homogeneity of variance. After ANOVA, means were separated using Duncan's multiple range test.

\section{Results}

\section{In-vivo contractile activity}

Spontaneous activity. EMG spikes were recorded from the MYO explant in all 3 animals and in the ENDO/MYO explant from 1 of the 3 animals in which recordings were begun 1-2 days after surgery. Initially the EMG spikes were of low amplitude $<20 \mu \mathrm{V}$. In one animal EMG bursts from the MYO strip, but not the ENDO/MYO strip, showed regular contracture-type bursts from Day 1 after surgery. In the other 2 animals, EMG activity was grouped in short irregular bursts $(<15 \mathrm{sec})$ or long extended bursts $(>8 \mathrm{~min})$. Uterine EMG activity exhibited the normal pattern at this time with EMG spikes $(\sim 500 \mu \mathrm{V})$ grouped in bursts of 5-8 min duration occurring with a frequency of 1-2/2 h. Over a period of 7-10 days EMG spikes were recorded from all of the explants (MYO and ENDO/MYO). During this time the EMG signals increased in amplitude and became organized into regular bursts of 3-5 min duration.

Observation of spontaneous myometrial activity was made in all 5 animals beginning on Day 125 and continuing for 7-12 days. As seen in Fig. 1, spontaneous EMG bursts were recorded from the MYO and ENDO/MYO explants and from the uterine myometrium. Of special note was the lack of synchrony between the EMG bursts from each of the 3 tissues. The amplitude of EMG spikes from the explant strips $(\sim 50-150 \mu \mathrm{V})$ was considerably less than that of the uterine myometrium $(\sim 500 \mu \mathrm{V})$. Over the 7-12-day observation period the frequency and duration of EMG bursts in both of the explants and in the uterine myometrium remained stable. The overall frequency of bursts in both the MYO $(5.3 \pm 0.2$ per $2 \mathrm{~h})$ and the ENDO/MYO $(5.2 \pm 0.3$ per $2 \mathrm{~h})$ explants was significantly $(P<0.05)$ greater than that in uterine myometrium $(3.0 \pm 0.1$ per $2 \mathrm{~h})$. In addition, the duration of EMG bursts was significantly $(P<0.05)$ less in the MYO $(4.1 \pm 0.2 \mathrm{~min})$ and ENDO/MYO $(4.1 \pm 0.2 \mathrm{~min})$ explants than in the uterine myometrium $(7 \cdot 3 \pm 0.1 \mathrm{~min})$. There were therefore no apparent differences in spontaneous EMG activity between the MYO and ENDO/MYO explants.

Oxytocin responses. Data were obtained from all 5 animals. In contrast to the asynchrony of spontaneous EMG bursts between each explant and the uterus, the injection of oxytocin resulted in simultaneous bursts of EMG activity from both of the explants at all doses and between explants and uterus at doses of 100 and $200 \mathrm{mU}$ (Fig. 2). In addition, the explants, as well as the uterus, exhibited a dose-response stimulation to oxytocin (50-200 mU; Fig. 3). On Day 125 the integrated 

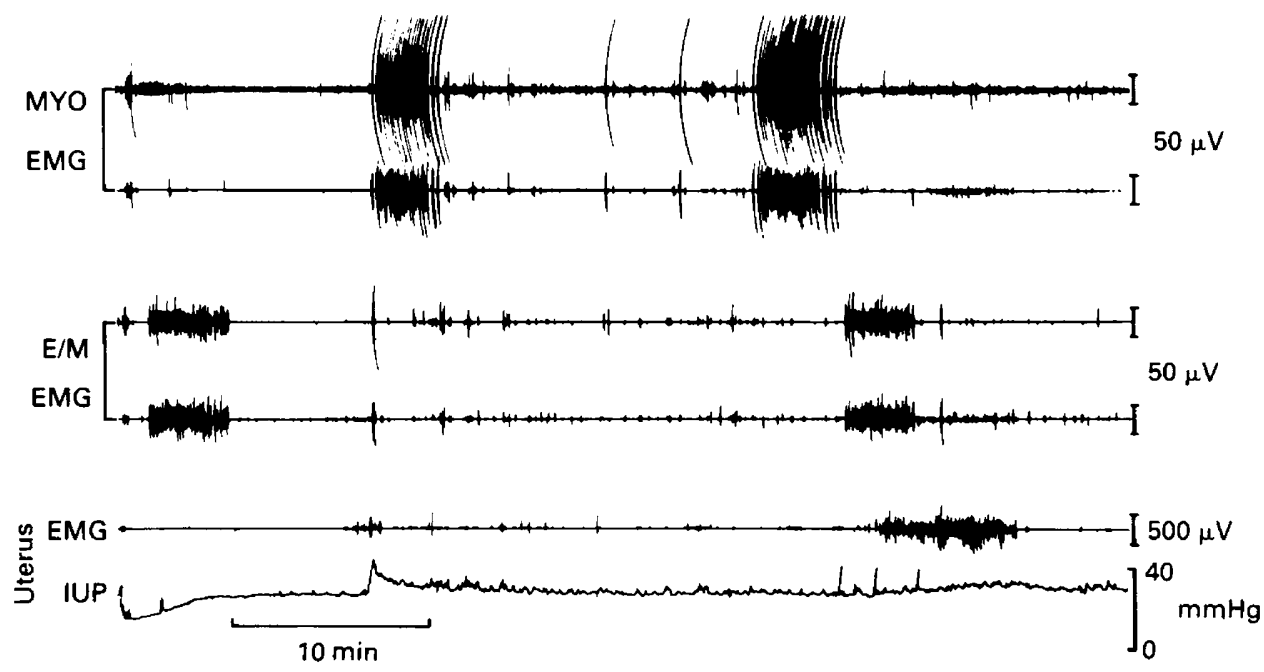

Fig. 1. Spontaneous activity of explants and uterine myometrium during pregnancy. The trace shows (from top) EMG activity from two electrodes on MYO explant; EMG activity from two electrodes on ENDO/MYO explant; uterine EMG activity; intrauterine pressure (IUP). Note the lack of synchrony between the spontaneous EMG bursts.
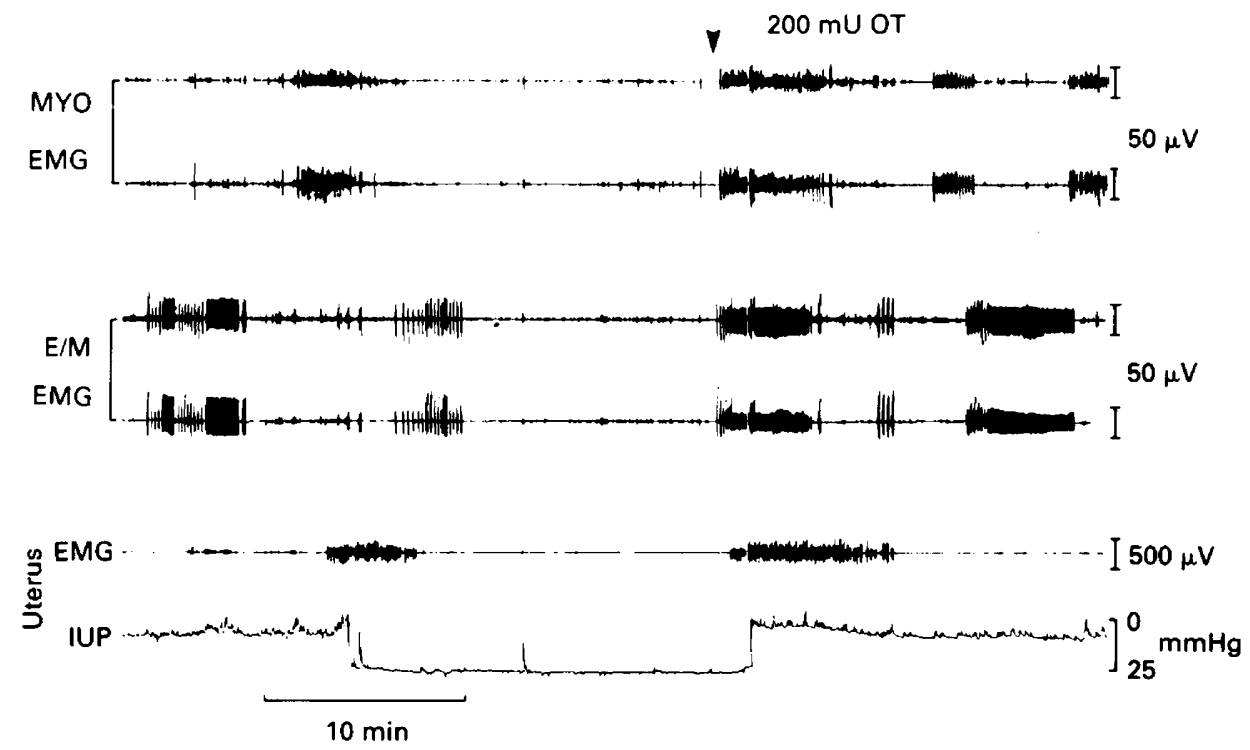

Fig. 2. Response of explants and uterus to oxytocin $(200 \mathrm{mU})$ administered as a bolus via the femoral vein catheter of the sheep. Note the synchrony of induced activity in all tissues.

response (over $30 \mathrm{~min}$ ) of the MYO explant to oxytocin was $2.0 \pm 0.4$ arbitrary units ( $50 \mathrm{mU}$ dose), $3.4 \pm 0.7(100 \mathrm{mU}$ dose) and $4.5 \pm 0.5(200 \mathrm{mU}$ dose; $P<0.05)$. These values did not change significantly throughout the period of study. Similar data were obtained for the ENDO/MYO explant and the uterus. There was no significant difference in oxytocin response between the MYO and ENDO/MYO explant.

During the course of this study we observed that, if oxytocin was administered $>15 \mathrm{~min}$ after a spontaneous contraction in one of the explants, the duration of the stimulus to response time was 


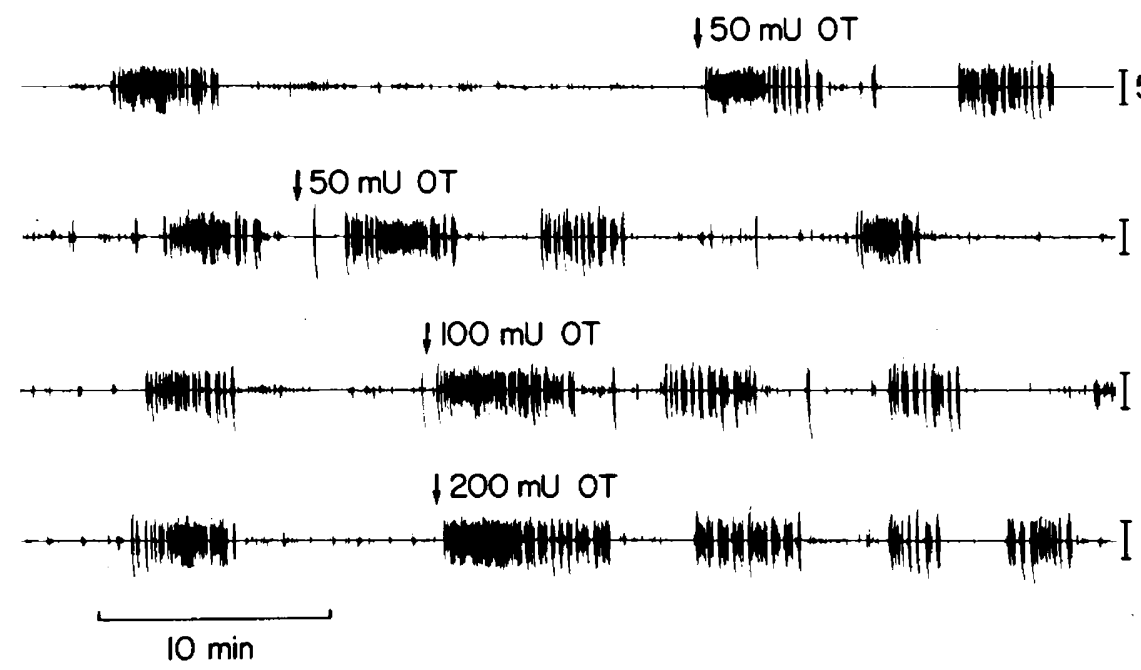

Fig. 3. Dose-response of MYO explant to oxytocin (50, 100 and $200 \mathrm{mU}$ OT) administered as bolus injections via the maternal femoral vein catheter. Note also the shorter stimulus-response time when oxytocin $(50 \mathrm{mU})$ was administered $>20 \mathrm{~min}$ after a spontaneous contracture compared with +5 min after.

reduced compared to that when the same dose of oxytocin was administered within 5 min after a spontaneous contracture (Fig. 3). Consequently, administration of oxytocin for all dose-response studies was conducted at +5 to +10 min after a spontaneous EMG burst from both explants and uterus. The stimulus-response time was also dose-dependent, with the highest doses producing a more rapid response than the lower ones. On Day 125 the stimulus-response (min) time was $6.6 \pm 0.7$ at $50 \mathrm{mU}, 1.9 \pm 0.7$ at $100 \mathrm{mU}$ and $1.5 \pm 0.7$ at $200 \mathrm{mU}$ oxytocin for the MYO explant and $10 \cdot 3 \pm 3 \cdot 2$ at $50 \mathrm{mU}, 8 \cdot 3 \pm 4 \cdot 0$ at $100 \mathrm{mU}$ and $4.4 \pm 1 \cdot 3$ at $200 \mathrm{mU}$ oxytocin for the uterine myometrium.

\section{In-vitro contractile activity}

In-vitro experiments were conducted on 3 of the 5 animals studied. Myometrial strips from both explant preparations displayed regular spontaneous contractions during in-vitro contraction studies. The frequency of these contractions $(3-4 / \mathrm{h})$ was similar to that observed in vivo. In addition, the explant strips showed a dose-response stimulation to cumulative additions of oxytocin within the range $10^{-10}$ to $10^{-4} \mathrm{M}$ (Fig. 4). The responsiveness of the explants to stimulation by oxytocin was similar to that of the uterine myometrium. A significant $(P<0.05)$ increase in contractile activity was first seen at $10^{-6} \mathrm{M}$-oxytocin for each tissue (MYO, ENDO/MYO and uterus).

\section{Histological examination}

Histological examination of the MYO and ENDO/MYO explants revealed the presence of smooth muscle cells arranged in bundles (Fig. 5). In general, there was also a clearly defined orientation of the smooth muscle into 2 layers at right angles to each other. This would be consistent with the maintenance of longitudinal and circular muscle layers within these explants. The presence of small blood vessels containing blood cells within the smooth muscle of the explants was also 

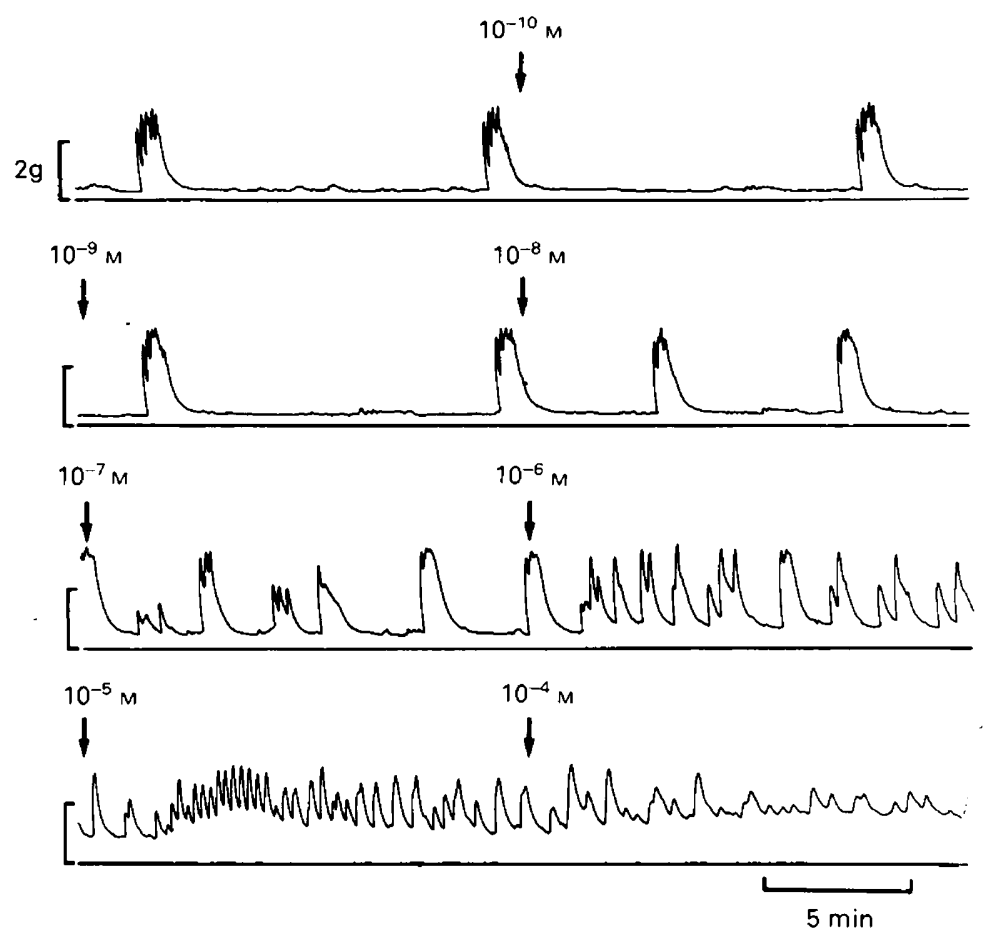

Fig. 4. In-vitro spontaneous and oxytocin-induced contractile activity of strip from an ENDO/MYO explant.

observed, although the degree of vascularization, as well as the total amount of smooth muscle was decreased compared with the uterine myometrium. There was an indication of replacement of some smooth muscle by fibrous connective tissue in the explants. Endometrial glands were present in the ENDO/MYO explant, although some were dilated and the epithelium of some of the glands showed signs of atrophy; others appeared functional (Fig. 5c). A limited degree of lymphocyte infiltration was apparent in some explants.

\section{Discussion}

We have described an experimental preparation which allows the in-vivo investigation of the role of local and systemic factors in the genesis of uterine contractures during pregnancy. Our results suggest that these contractures are not due to the pulsatile release of stimulants into the systemic circulation but are probably mediated by local events within the myometrium itself.

Our experimental preparation is a modification and extension of a technique described by Sigger et al. (1984b). These authors removed the tip of the pregnant uterine horn including, on occasions, the fetal membranes and placed it in the omental fat. In our preparation we have attempted to control for a number of factors which are either known or suspected to affect myometrial contractile activity. We have thus maintained the in-situ degree of stretch on the myometrium by the attachment of the strip to a stainless steel frame. The maintenance of tension (stretch) within the myometrium has been reported as a significant factor in the control of contractile activity (Finn \& Porter, 1975) and in the development of myometrial gap junctions (Wathes \& Porter, 1982). Stretch has also been shown to affect the electrical activity of the oviduct (Daniel $e t$ 


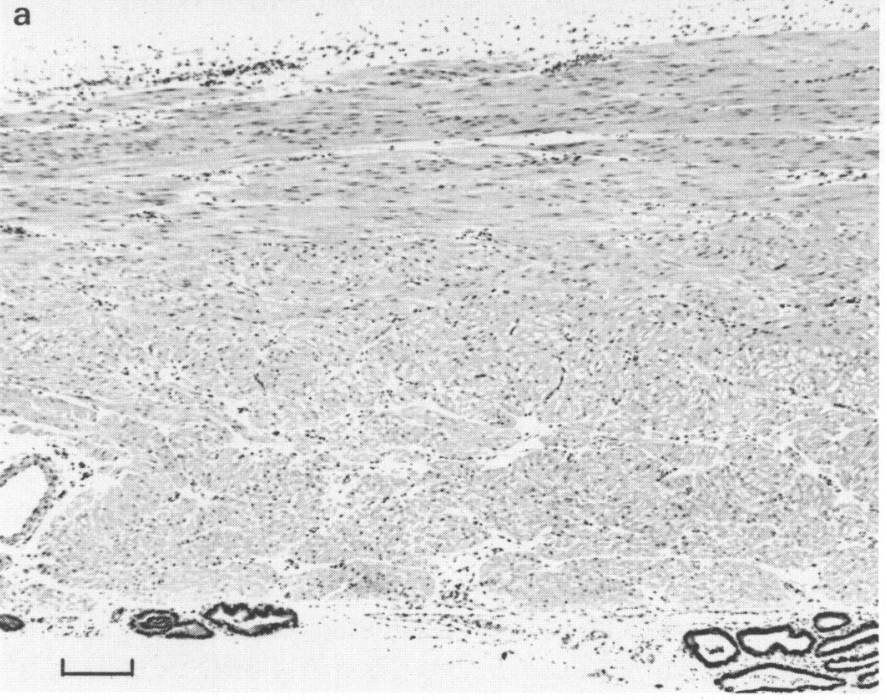

b

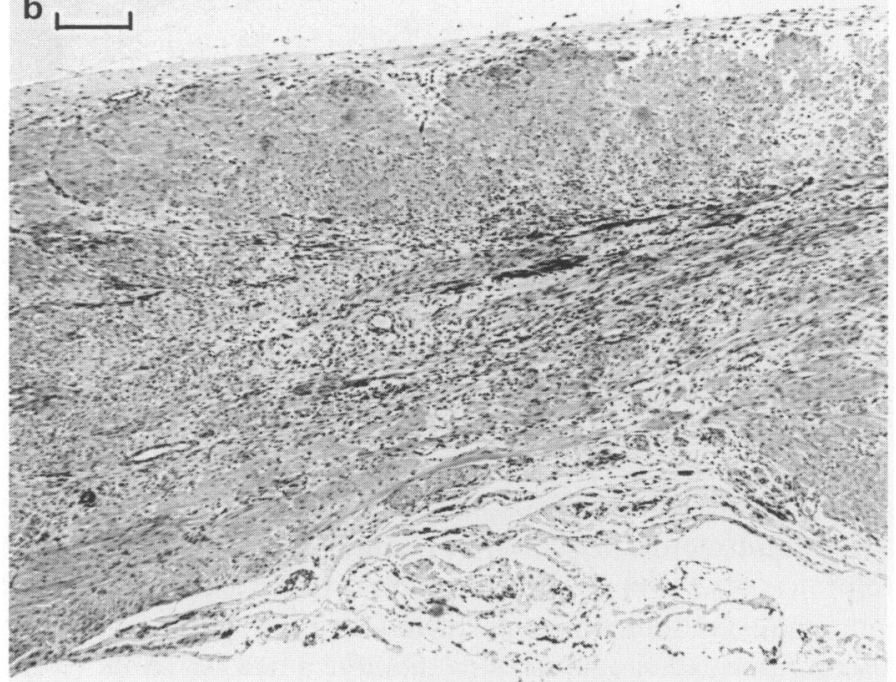

C

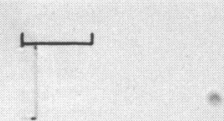

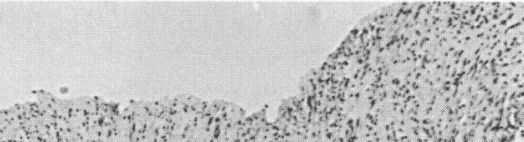

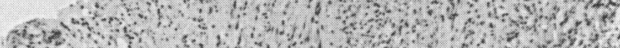

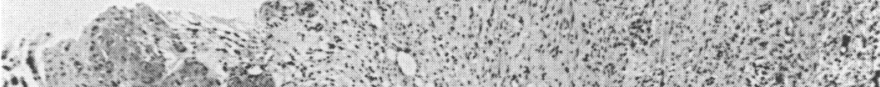

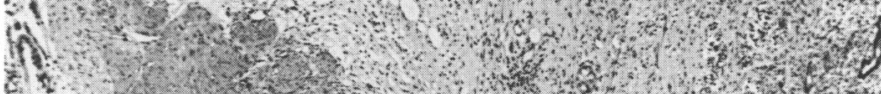

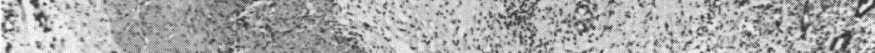
t. 2.

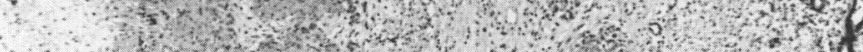

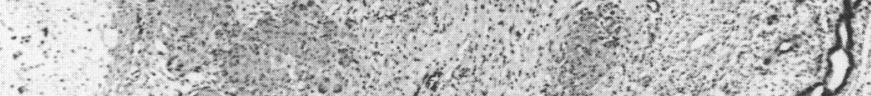

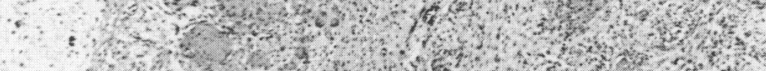

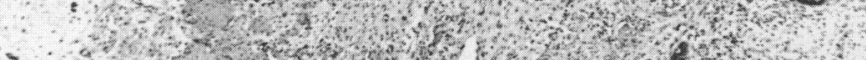

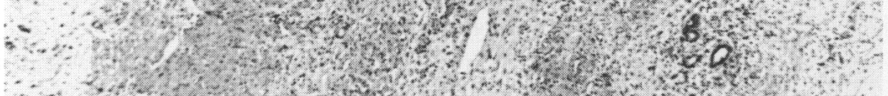

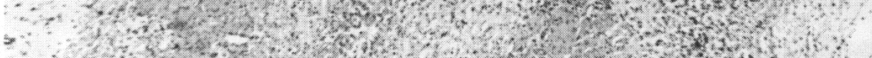

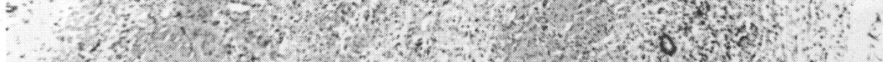

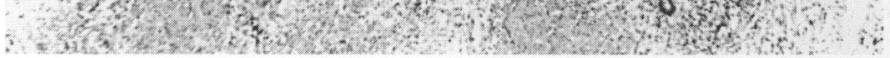


al., 1975). This procedure may explain the presence of smooth muscle bundles in our explants arranged in a clearly defined 'longitudinal' and 'circular' orientation as compared with the lack of regular orientation found by Sigger et al. $(1984 \mathrm{~b})$. This preparation also allows the examination of the contractile activity of myometrial tissue alone (i.e. in the absence of other intrauterine tissues which are known to produce substances that can inhibit or stimulate the myometrium). Finally, we have validated the mechanical integrity of the explants by confirming their ability to develop spontaneous contractions and respond (in a dose-dependent fashion) to oxytocin in vitro. We did not detect any difference in in-vitro sensitivity of explants or uterine myometrium to oxytocin. However, the magnitude of tension developed by the uterine myometrium in vitro was greater than that of the MYO and ENDO/MYO explants, perhaps indicative of some loss of smooth muscle as was apparent in the histological examination.

Our rejection of a systemic stimulus to the production of uterine contractures during pregnancy supports the findings of Sigger et al. (1984b). Both studies based their conclusions on (a) the higher frequency of EMG bursts in the isolated as compared to the uterine myometrium, and (b) the lack of synchrony between EMG bursts of the isolated myometrium and those of the uterine myometrium. It could be argued, however, that the inability of the different tissues to respond in synchrony to circulating stimulants was caused by an alteration in the delivery of the stimulant to the myometrium. This might be due to a disruption of blood supply or the positioning of the isolated tissue in a different vascular bed. We examined this possibility by observing the responses to oxytocin injected into the peripheral circulation. Our finding that such injections produce synchronous EMG bursts in explants and uterus suggests that delivery of such stimulants is not compromised in this preparation. Evidence against a role for oxytocin in the genesis of contractures was also provided by Garcia-Villar et al. (1983). These authors were unable to find pulsatile increases in plasma oxytocin temporally associated with contractures.

It may be, therefore, that uterine contractures are produced by local mechanisms within the myometrium. This could be due to some inherent myogenic activity (Daniel et al., 1975) or possibly a paracrine/autocrine stimulation. El Badry et al. (1984) have suggested that contractures may develop due to stimulatory PGs; they found a decrease in the frequency of contractures and in 13,14-dihydro-15-keto PGF-2 $\alpha$ (PGFM: the circulating metabolite of PGF-2 $\alpha$ ) concentrations following an infusion of 4-aminoantipyrine to pregnant ewes. However, studies using meclofenamic acid (MFA: an inhibitor of PG synthesis) in doses sufficient to block premature labour did not report a decrease in the occurrence of contractures (Mitchell \& Flint, 1978). In preliminary studies using MFA and also indomethacin we have also been unable to block the occurrence of contractures. It remains to be seen whether this difference reflects an increased potency of antipyrine or whether this drug exerts additional effects either on the production of other arachidonic acid metabolites or directly on the myometrium.

Release of the myometrium from periods of refractoriness might also account for the regular occurrence of contractures throughout pregnancy. Our observation that the onset of an induced contracture was more rapid if oxytocin was administered $>15 \mathrm{~min}$ after a spontaneous contracture, together with the observation that single EMG spikes are reduced immediately after a spontaneous burst of EMG activity (Harding et al., 1982) are consistent with the existence of refractory periods. Preliminary studies in non-pregnant sheep have also revealed that the interval from administration of oxytocin to the induced-burst of EMG activity (contractures) in myometrial explants was significantly greater $(P<0.05)$ at +1 min than at +15 min after a spontaneous contracture (S. J. Lye, unpublished observations). Although these data are supportive of the existence of refractory periods, such a state has yet to be proven. In the context of studies

Fig. 5. Histological sections from (a) uterine myometrium; (b) MYO explant, and (c) ENDO/MYO explant. Calibration bars represent $0.22 \mathrm{~mm}$. 
such as the present one in which in-vivo dose-responses to oxytocin are examined, it may be necessary to standardize the time of administration of this agonist with respect to spontaneous contractile activity.

An explanation for the increased frequency and decreased duration of explant EMG bursts compared with the uterine myometrium is not readily apparent. In the rat uterus electrical activity (and resulting contractile activity) is initiated in discrete but mobile pacemaker regions (Lodge \& Sproat, 1981). Our data (from myometrial tissue from the mid-uterine horn region), together with that of Sigger et al. (1984b), who found a similar increase in frequency of EMG bursts from the isolated tip of the uterine horn, suggest that this does not represent differences in pacemaker activity within different regions of the uterus. In the intestinal tract myogenic activity may be controlled by cells within the circular muscle layer producing an 'Electrical Control Activity' (ECA: Daniel \& Sarna, 1978). The extent to which similar mechanisms occur in the myometrium remains to be determined. The electrical activity of myometrial cells from placental regions is suppressed compared with non-placental regions in the rat uterus (Kanda \& Kuriyama, 1980) possibly due to locally acting placental progesterone (Csapo, 1961). It is possible, therefore, that the exposure of the myometrial explants to the lower progesterone concentrations of the peripheral circulation might reduce an inhibitory action of this or any other hormones produced by intrauterine tissues, and lead to an increased frequency of contraction.

In this study we found no differences between the MYO or ENDO/MYO explants in their in-vivo electrical activity or in-vitro contractile activity. While this might suggest that the endometrium does not influence the contractile activity of the myometrium, the histological evidence suggested that there may be some impairment of function in the endometrial tissue. It might be that the endometrial tissue can less readily withstand the initial loss of vascular supply following transplantation. Histochemical and/or hormone content measurements will be required to resolve the question of the role of the endometrium.

In conclusion, we have described a preparation that allows the investigation of EMG activity from isolated myometrial tissue in vivo. We have obtained data to suggest that uterine contractures during pregnancy are not due to pulsatile release of stimulatory substances into the systemic circulation. We believe that this preparation will be of use in examining in vivo many characteristics of myometrial activity that are currently studied in vitro.

We thank Mrs Julie Brooks for assistance with data analysis; Mrs Nan Cumming for assistance with preparation of the manuscript; and $\mathrm{Mr}$ J. Bousquet and his staff for care of the animals. This research was supported by the Medical Research Council of Canada (MA9244, S.J.L.). S.J.L. is an Ontario Ministry of Health Career Scientist.

\section{References}

Csapo, A.I. (1961) Defence mechanism of pregnancy. Ciba Fdn Study Group 9, 3-26. Churchill, London.

Csapo, A.I. \& Sauvage, J. (1968) The evolution of uterine activity during human pregnancy. Acta obstet. gynec. scand. 47, 181-212.

Daniel, E.E. \& Sarna, S. (1978) The generation and conduction of activity in smooth muscle. Ann. Rev. Pharmacol. Toxicol. 18, 145-166.

Daniel, E.E., Lucien, P., Posey, V.A. \& Paton, D.M. (1975) A functional analysis of the myogenic control systems of the human Fallopian tube. Am. J. Obstet. Gynecol. 121, 1046-1053.

Demianczuk, N., Towell, M.E. \& Garfield, R.E. (1984) Myometrial electrophysiological activity and gap junctions in the pregnant rabbit. Am. J. Obstet. Gynecol. 149, 485-491.
El Badry, A., Figueroa, J.P., Poore, E.R., Sunderji, S., Levine, S., Mitchell, M.D. \& Nathanielsz, P.W. (1984) Effect of fetal intravascular 4-aminoantipyrine infusions on myometrial activity (contractures) at 125-143 days' gestation in the pregnant sheep. Am.J. Obstet. Gynecol. 150, 474-479.

Finn, C.A. \& Porter, D.G. (1975) The Uterus. Elek Science, London.

Fuchs, A-R. (1969) Uterine activity in late pregnancy and during parturition in the rat. Biol. Reprod. 1, $344-353$.

Garcia-Villar, R., Toutain, P.L., Schams, D. \& Ruckebusch, Y. (1983) Are regular activity cycles of the genital tract controlled by pulsatile releases of oxytocin. Biol. Reprod. 29, 1183-1188.

Garcia-Villar, R., Toutain, P.L. \& Ruckebusch, Y. (1984) 
Patterns of electrical activity of the ovine uterus and cervix from mating to parturition. J. Reprod. Fert. 72, 143-152.

Germain, G., Cabrol, D., Visser, A. \& Sultan, C. (1982) Electrical activity of the pregnant uterus of the cynomolgus monkey. Am. J. Obstet. Gynecol. 142, $513-519$.

Harding, R., Poore, E.R., Bailey, A., Thorburn, G.D., Jansen, C.A.M. \& Nathanielsz, P.W. (1982) Electromyographic activity of the nonpregnant and pregnant sheep uterus. Am. J. Obstet. Gynecol. 142, $448-457$.

Hindson, J.C. \& Ward, W.R. (1973) Myometrial studies in pregnant sheep. In The Endocrinology of Pregnancy and Parturition, pp. 153-162. Ed. C. G. Pierrepoint. Alpha Omega Alpha, Cardiff.

Jansen, C.A.M., Krane, E.J., Thomas, A.L., Beck, N.F.G., Lowe, K.C., Joyce, P., Parr, M. \& Nathanielsz, P.W. (1979) Continuous variability of fetal $\mathrm{PaO} 2$ in the chronically catheterized fetal sheep. Am. J. Obstet. Gynecol. 134, 766-783.

Kanda, S. \& Kuriyama, H. (1980) Specific features of smooth muscle cells recorded from the placental region of the myometrium of pregnant rats. $J$. Physiol., Lond. 289, 127-144.

Lodge, S. \& Sproat, J. (1981) Resting membrane potentials of pacemaker and non-pacemaker area in the rat uterus. Life Sci. 28, 2251-2256.

Lye, S.J., Sprague, C.L., Mitchell, B.F. \& Challis, J.R.G. (1983) Activation of ovine fetal adrenal function by pulsatile or continuous administration of adrenocorticotropin (1-24). I. Effects on fetal plasma corticosteroids. Endocrinology 113, 770-776.

Lye, S.J., Wlodek, M.E. \& Challis, J.R.G. (1984) Relation between fetal arterial PO2 and oxytocininduced uterine contractions in pregnant sheep. Can. J. Physiol. Pharmacol 62, 1337-1340.

Lye, S.J., Wlodek, M.E. \& Challis, J.R.G. (1985) Possible role of uterine contractions in the short-term fluctuations of plasma ACTH concentrations in fetal sheep. J. Endocr. 106, R9-RI1.

Mitchell, M.D. \& Flint, A.P. (1978) Use of meclofenamic acid to investigate the role of prostaglandin biosynthesis during induced parturition in sheep. J. Endocr. 76, 101-109.

Mitchell, M.D., Kraimer, D.L., Brennecke, S.P. \& Webb, R. (1982) Pulsatile release of oxytocin during the oestrous cycle, pregnancy and parturition in sheep. Biol. Reprod. 27, 1169-1173.

Nathanielsz, P.W., Ratter, S., Thomas, A.L., Rees, L. \& Jack, P.M.B. (1976) The role and regulation of ACTH in the fetal sheep. In The Fetus and Birth (CIBA Fdn Symp. 47), pp. 73-91. Elsevier, Amsterdam.
Nathanielsz, P.W., Bailey, A., Poore, E.R., Thorburn, G.D. \& Harding, R. (1980) The relationship between myometrial activity and sleep state and breathing in fetal sheep throughout the last third of gestation. $A m$. J. Obstet. Gynecol. 138, 653.

Porter, D.G. (1971) Quantitative changes in myometrial activity in the guinea-pig during pregnancy. $J$. Reprod. Fert. 27, 219-226.

Ruckebusch, Y. \& Bueno, L. (1976) An electromyographic study of uterotubal activity in the ewe. $J$. Reprod. Fert. 47, 221-227.

Sigger, J.N., Harding, R. \& Bailey, A. (1984a) Development of myometrial activity during the first half of pregnancy in the sheep. Aust. J. biol. Sci. 37, 153-162.

Sigger, J.N., Harding, R. \& Jenkin, G. (1984b) Relationship between electrical activity of the uterus and surgically isolated myometrium in the pregnant and non-pregnant ewe. J. Reprod. Fert. 70, 103-114.

Sunderji, S.G., El Badry, A., Poore, E.R., Figueroa, J.P. \& Nathanielsz, P.W. (1984) The effect of myometrial contractures on uterine blood flow in the pregnant sheep at 114-140 days' gestation measured by the 4-aminoantipurine equilibrium diffusion technique. Am. J. Obstet. Gynecol. 149, 408-412.

Toutain, P.L., Garcia-Villar, R., Hazen, C. \& Ruckebusch, Y. (1983) Electrical and mechanical activity of the ewe during pregnancy and parturition. J. Reprod. Fert. 68, 195-204.

Van der Weyden, G.C., Taverne, M.A.M., Dieleman, S.J. \& Fontijne, P. (1981) Myometrial electrical activity throughout the entire course of pregnancy in the ewe. Eur. J. Obstet. Gynecol. Reprod. Biol. 11, 347-354.

Wagner, G. (1975) Function of myometrial graft at the time of parturition in the rabbit. Acta endocr., Copenh. 79, 778-788.

Wathes, D.C. \& Porter, D.G. (1982) Effect of uterine distension and oestrogen treatment on gap junction formation in the myometrium of the rat. $J$. Reprod. Fert. 65, 497-505.

Windmoller, R., Lye, S.J. \& Challis, J.R.G. (1983) Estradiol modulation of ovine uterine activity. Can. J. Physiol. Pharmacol. 61, 722-728. 